\title{
Timetabling mathematical model for an Industrial Engineering program: the case of a Colombian Higher Education Institution
}

\author{
Modelo matemático para la programación de horarios de clase de un programa de \\ Ingeniería Industrial: El caso de una Institución de Educación Superior Colombiana
}

MERA-BANGUERO, Jorge A. ${ }^{1}$

BRAVO-BASTIDAS, Juan J.2

\begin{abstract}
This article presents a mixed integer programming model designed to organize classes, teachers and classrooms considering time slots, defining an optimal schedule for the Industrial Engineering program of a Higher Education Institution (HEI) in Colombia. 63 courses were included with requirements associated with teachers, class days, possible crossovers, class divisions, and others. The schedule generated by the model provides useful information to the institution and opens the possibility of expanding the use of the model with a greater scope.

Key words: timetabling problem, higher education institution, mixed integer linear programming

Resumen

Este artículo presenta un modelo de programación lineal entera mixta, diseñado para organizar las clases, profesores y salones considerando franjas horarias, definiendo un horario óptimo para el programa de Ingeniería Industrial de una Institución de Educación Superior (IES) en Colombia. Fueron incluidas 63 asignaturas con requerimientos asociados a profesores, días de clase, posibles cruces, divisiones de clases y otros. El horario óptimo generado por el modelo, proporciona información útil a la institución y abre la posibilidad de ampliar el uso del modelo con un alcance mayor.

Palabras clave: problema de programación de horarios, institución de educación superior, programación lineal entera mixta
\end{abstract}

\section{Introduction}

The timetabling problem is a common problem in all educational institutions and although its complexity may vary according to the particularities of each organization, the problem will always be oriented to cover the academic activities established with the available resources. Wren (1996) determined the timetabling as a special assignment problem and defines it as: "the allocation, subject to constraints, of given resources to objects being placed in space-time, in such a way as to satisfy as nearly as possible a set of desirable objectives".

\footnotetext{
${ }^{1}$ Profesor Asociado. Director de programa Ingeniería Industrial. Corporación universitaria Comfacauca. Colombia. dirindustrialzonanorte@unicomfacauca.edu.co

2 Profesor Asociado. Escuela de Ingeniería Industrial.Universidad del Valle. Colombia. juan.bravo@correounivalle.edu.co
} 
In the literature review, we can see a large number of applications for this type of problem, which is classified as NP-hard. This demonstrates the great interest of academic community in this interesting topic, creating new innovative ways to model the problem and obtain optimal solutions.

In the HEl under study, the associated timetabling problem has been performed with complex spreadsheets, which are not as efficient as needed. This method has generated inefficiencies in the Institution's resources, since it requires full-time personnel dedicated for a week to this programming activity. This context has opened the possibility to develop a mathematical programming model in order to get the objective in a better and more efficient way. For this research, the Industrial Engineering program was selected as a pilot and this article shows the developed model its usefulness and practical implications.

The use of optimization models in real life may sometimes not be possible due to financial and other limitations. That is why it is very useful to perform pilot tests with the use of optimization models with which important doors are opened for larger-scale implementations in reality.

\section{Methods}

\subsection{Literature review}

Timetabling problems associated with class schedules are difficult tasks faced by educational institutions. Sometimes, the institutions solve the problem manually but this the task becomes impractical when there are large amount of events, resources and restrictions that must be managed (Fonseca, Santos, Carrano, \& Stidsen, 2017). In these cases, optimization methods are used to generate the timetabling, with significantly better results, so that the institution can use its resources more efficiently. In 1976, Even, Itai, \& Shamir stated the big complexity of this type of problem which were classified as NP-hard.

Babaei, Karimpour, \& Hadidi, (2015) present the basic definitions for any timetabling problem such as: event, which refers to the activity or course to be scheduled; time slots, corresponds to the day and time when the classes must be scheduled; resources, corresponds to the materials and environments that are needed for the development of the classes; constraints, correspond to the conditions required in the scheduling of events; conflicts, the possibility that two events are scheduled at the same time and space. Similar criteria for the development of each model are observed in many papers, as presented by Esquivel \& Orejuela (2019), Babaei et al., (2015), Song, Liu, Tang, Peng, \& Chen (2018), where teachers, classrooms, courses, time spaces and students are established as sets of the model.

Regarding the constraints, there are two types: hard and soft constraints. The first ones refer to mandatory constraints which seek to satisfy the main considerations avoiding any possible conflict, while the second ones are used to improve the solution quality (Babaei et al., 2015).

In the literature, a great variety of proposed models can be observed. Esquivel \& Orejuela (2019) presents a review of papers that have developed different optimization methods, classifying them in exact methods and metaheuristics, and it is clear a notable tendency to use exact methods as the solution methodology. Torres et al. (2014), use an exact method to solve the timetabling problem in a real case at the Universidad de la Sabana, Colombia. They design an integer linear programming model that was solved in a hierarchical way: first, it is defined the course schedule and, after that, the classrooms assignment is performed. The authors validate the approach by using real data, ending with a sensitivity analysis that allowed verifying the possibility of reducing both the number of classrooms assigned and the number of groups of courses.

Heitmann \& Brüggemann (2014), present a case at the School of Business, Economics and Social Sciences of the University of Hamburg, Germany. In this study, 3,735 students have to be assigned to 48 courses in 300 multiple 
teaching groups, so that no student has a time crossing and also the enrollment as well as group capacities are met. The objective was the satisfaction of students with respect to the preferences, specified individually, for various aspects of the scheduling. A mixed integer programming model was designed and solved using GAMS and the CPLEX solver.

Dorneles, De Araújo, \& Buriol (2014) present a mixed integer linear programming (MILP) model and an optimization methodology that also uses the variable neighborhood method. They perform three different types of decompositions: class, teacher, and day, to solve the problem at a high school. Kristiansen, Sørensen, \& Stidsen (2015) also use a MILP model which is solved in two steps with a commercial solver.

Despite many problems have been solved with exact methods and commercial solvers, other authors present different optimization methods depending on the solution difficulties associated with the number of elements of the problem and system. As examples we can consider the articles written by Toune, Fudo, Genji, Fukuyama, \& Nakanishi (2002) who apply the Particle Swarm Optimization (PSO) and Artificial Fish Swarm (AFS) algorithms to the timetabling problem in a high school. Moreover, Thepphakorn, Pongcharoen, \& Hicks (2014) use the Ant Colony Optimization metaheutristics.

Observing these and other papers, it is easy to observe that the models include some sort of generic constraints, common to observe in real life cases, and also other particular limitations that depends on the operative characteristics of the analyzed institution. In addition, some complex methods have been used to solve the resultant modeling strategy. However, it is the scope of the model and the number of elements in it that define if an exact method is enough or if, perhaps, it is needed other solution approaches. In this article, an MILP model was designed in a real "pilot" case and the solution was obtained using AMPL and CPLEX solver.

\subsection{Case study}

As stated before, the HEI under analysis (whose name is omitted due to confidentiality requirements) solves the real timetabling problem manually with the support of a non-optimized spreadsheet. Obviously, considering the big complexity of this type of problem, the results obtained are not optimal and the programming process is very time-consuming. Therefore, the need of a formal model of the problem is clear and justified. To start with the modeling of the problem, a pilot case was selected, and the institution provided the data of the Industrial Engineering program, which currently has 576 students, which have to use 14 classroom at day time, and 20 classroom at nigh time, according to the classes that need to be scheduled and availability of teachers.

Some difficulties found in the current strategy were relevant and it was necessary to adjust them. Teachers are first assigned according to their profiles, taking into account that a teacher cannot be assigned to two classes at the same time. Also, according to the number of students enrolled in a course, the assignment of classrooms depends on the availability of them in each time slot. It is necessary to consider that some teachers require specific spaces due to the methodology of the classes, to carry out laboratory practices. Sometimes, the availability of all rooms is not available and other spaces such as computer rooms or laboratories with a smaller capacity must be used. Lastly, some teachers are taking postgraduate studies, which reduces their availability for undergraduate classes.

Other inconveniences appear when, in some cases, two classes were assigned at the same time in the same room with different teachers and subjects, which generates conflicts affecting the provision of service and user satisfaction. It has also happened that a teacher was assigned at the same time in two different classes and classrooms. When these cases appeared, some complaints emerged which affect the image of the organization. 
Therefore, the following optimization model seeks to solve the problem as best as possible, and the results will serve as a basis for extending the application of the model to other academic programs and faculties.

\subsection{Timetabling problem characterization}

\subsubsection{General information of the case study}

In its curriculum, the program has 65 courses ordered in 10 academic semesters that are divided into six semesters of 17 credits and four of 18 academic credits. At the HEl under study, one credit corresponds to one hour of face-to-face class and two hours of independent work.

The courses have hourly intensities of 1,2,3,4 and 6 hours, distributed as follows: one 1-hour course, 25 2-hour courses, 35 3-hour courses, 3 4-hour courses and one 6-hour course.

There are a total of 23 teachers and each one of them has a set of possible courses to be assigned.

For the Industrial Engineering program, ten regular rooms are available, two computer rooms and two laboratories. The computer rooms and laboratories are programmed for special cases according to the courses for practical work only, and they are not suitable for giving a regular class. The classroom capacity is between 45 and 50 students.

\subsubsection{Considerations and assumptions}

The following aspects were relevant in the modeling process:

- The available weektime ranged from Monday to Saturday, in sequential 4 hours per day.

- The 4-hour courses must be divided into two 2-hour slots on two different days. The 2-hour or 3-hour courses must be performed in one day without splits. So, in one day, a maximum of two 2-hour courses or one 3-hour course can be assigned. There is a 1-hour and a 6-hour course that are not face-to-face. They are worked through seminars that are scheduled at any time.

- Each course must be assigned to a teacher and to a class-room in an established time slot. All teachers must have as-signed at least one course. It should be avoided that two teachers be assigned to exactly the same course. In each classroom, each day, only one teacher and one course can be assigned. In the case study, is mandatory to prevent any kind of crossing between classes, classrooms, teachers and time,

- The number of students assigned to a course cannot exceed classroom capacity.

- Each teacher can only be assigned maximum once, in a day, for a 3-hour course. Each teacher can only be assigned max-imum twice, in a day, for 2-hour courses.

Additionally, students require that classes be preferably scheduled from Monday to Friday, avoiding Saturdays. The explanation for this requirement is that $60 \%$ of students work and must ask for permission to attend classes, avoiding enrolling courses on Saturdays.

\subsection{Mathematical formulation}

The model considers the six steps shown in Figure 1. 
Figure 1

Process of formulation a mathematical model

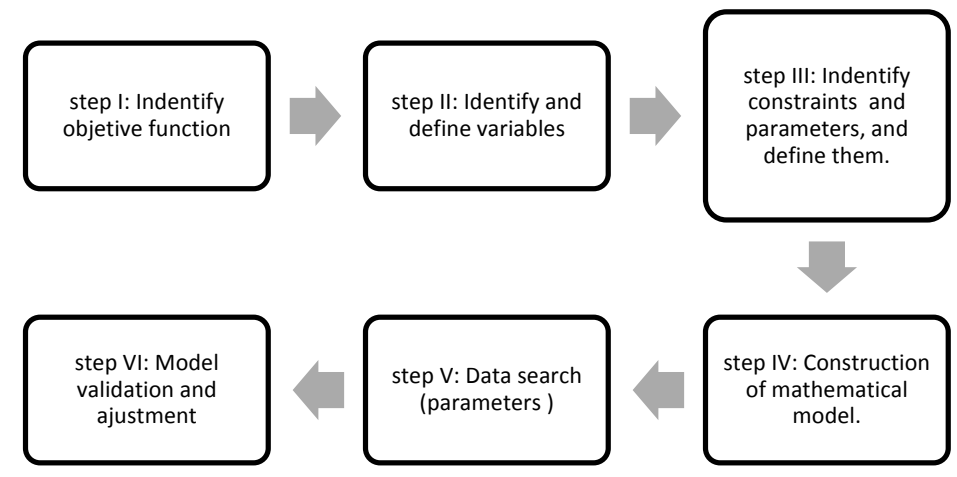

Source: Bravo (2013)

\subsubsection{Objective function}

The objective function seeks that all courses be properly scheduled: maximize the number of subjects scheduled. This objective is inspired by a real case and that is why we focus only on it. However, it is clear that there are many other objectives that have been used in the reviewed articles, many of which may make sense later in future work, when the administrators of the analyzed institution recognize other ways of establishing their objectives within the problem they are facing.

\subsubsection{Sets and subsets}

Tables 1 and 2 show the sets and subsets used in the model.

Table 1

Sets

\begin{tabular}{|c|c|c|}
\hline \multicolumn{3}{|c|}{ SETS } \\
\hline SALON & $\{\mathrm{s} 1, \mathrm{~s} 2, \mathrm{~s} 2 \ldots \mathrm{n}\}$ & indexed by $\mathrm{i}$ \\
\hline DIA & $\{\mathrm{d} 1, \mathrm{~d} 2, \mathrm{~d} 3 \ldots \mathrm{m}\}$ & indexed by $\mathrm{d}$ \\
\hline ASIGNATURA & $\{\mathrm{a} 1, \mathrm{a} 2, \mathrm{a} 3 \ldots \mathrm{o}\}$ & indexed by $\mathrm{j}$ \\
\hline SEMESTRE & $\{\mathrm{sem} 1, \mathrm{sem} 2, \mathrm{sem} 3 \ldots \mathrm{p}\}$ & indexed by $\mathrm{s}$ \\
\hline BLOQUEH & $\{\mathrm{b} 1, \mathrm{~b} 2 . . \mathrm{r}\}$ & indexed by $\mathrm{b}$ \\
\hline PROFESSOR & $\{\mathrm{p} 1, \mathrm{p} 2, \mathrm{p} 3 \ldots \mathrm{t}\}$ & indexed by $\mathrm{k}$ \\
\hline
\end{tabular}

Source: Authors

Table 2

Subsets

\begin{tabular}{|c|c|}
\hline \multicolumn{2}{|r|}{ SUBSETS } \\
\hline 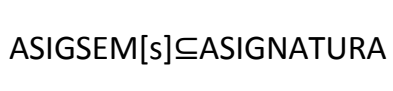 & $\begin{array}{c}\text { The elements of the set ASIGNATURA that are } \\
\text { related to a semester } s \in \text { SEMESTRE }\end{array}$ \\
\hline ASIGBLO $[\mathrm{b}] \subseteq A S I G N A T U R A$ & $\begin{array}{c}\text { The elements of the set ASIGNATURA that are } \\
\text { related a time block } b \in \text { BLOQUEH }\end{array}$ \\
\hline 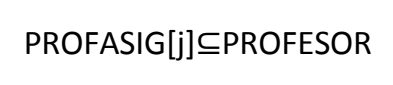 & $\begin{array}{c}\text { The elements of the set PROFESOR that are } \\
\text { related to a subject } j \in \text { ASIGNATURA }\end{array}$ \\
\hline
\end{tabular}

Source: Authors 


\subsubsection{Decision variable}

A robust binary variable $X_{i s b j k d}$ was defined, which allows scheduling a course from an academic semester with a teacher in a classroom, in one day in a time slot, or not.

1, If in the classroom $i \in S A L O N$ in the semester $s \in$ SEMESTRE in the time block $b \in$ BLOQUEH, the subject $\mathrm{j} \in[$ ASIGSEM[s] $\cap$ ASIBLOG[b]] is assigned taught by teacher $k \in$ PROFASIG[j], on day $d \in$ DIA

$X_{\text {isbjkd }}$

$0, \quad$ otherwise

\subsubsection{Parameters}

Table 3 presents the definition of parameters.

Table 3

Parameters

\begin{tabular}{|c|c|}
\hline \multicolumn{2}{|c|}{ PARAMETERS } \\
\hline $\begin{array}{c}\text { BLOQUEH (time } \\
\text { slot type) }\end{array}$ & $1=3$ hour time slots; 2 = 2 hour time slots \\
\hline $\mathrm{Pj}$ & $\begin{array}{l}\text { Times a week that the class } \mathrm{j} \in \text { ASIGNATURA } \\
\text { will be taught }\end{array}$ \\
\hline $\mathrm{CAPi}$ & Capacity of classroom i $\in$ SALON \\
\hline ESTj & Number of students for the course $\mathrm{j} \in$ ASIGNATURA \\
\hline
\end{tabular}

\subsubsection{Constraints}

\section{Classroom constraints:}

For BLOQUEH = 1:

In a classroom i for each day $d$, it must be scheduled at most one course $\mathrm{j}[\mathrm{s}$ ] of a semester $\mathrm{s}$ and type- 1 time slot with a teacher $\mathrm{k}$

$$
\begin{aligned}
& \sum_{s \in S E M E S T R E} \sum_{j \in A S I G S E M[s]} \sum_{k \in P R O F A S I G[j]} X_{i s 1 j k d} \leq 1 ; \\
& \forall i \in S A L O N, \quad \forall d \in D I A, \quad b=1
\end{aligned}
$$

For BLOQUEH = 2:

In a classroom i for each day $\mathrm{d}$, it must be scheduled at most one subject j[s] of a semester $\mathrm{s}$ and type- 2 time slot with a teacher $\mathrm{k}$

$$
\begin{aligned}
& \sum_{s \in S E M E S T R E} \sum_{j \in A S I G S E M[s]} \sum_{k \in P R O F A S I G[j]} X_{i s 2 j k d} \leq 2 ; \\
& \forall i \in S A L O N, \quad \forall d \in D I A, \quad b=2
\end{aligned}
$$


Another constraint was created to avoid the conflict between the two previous constraints. In a classroom i for each day $d$, it must be scheduled at most one class of the type- 1 time slot or two classes of the type-2 time slot.

$$
\begin{gathered}
\sum_{S \in S E M E S T R E} \sum_{j \in A S I G S E M[s]} \sum_{k \in \text { PROFASIG[j] }} X_{i s 1 j k d}+\frac{\sum_{s \in S E M E S T R E} \sum_{j \in A S I G S E M[s]} \sum_{k \in \text { PROFASIG }[j] X_{i s 2 j k d}}}{2} \leq 1 ; \\
\forall i \in \text { SALON, } \forall d \in D I A
\end{gathered}
$$

\section{For courses:}

Each course $\mathrm{j}$ of a semester $\mathrm{s}$ and with a time slot $\mathrm{b}$, in a day, must be scheduled at most once in a classroom $\mathrm{i}$.

$$
\sum_{i \in \text { SALON }} X_{i s b j k d} \leq 1
$$

$\forall d \in D I A, \forall s \in S E M E S T R E, \forall b \in B L O Q U E H, \forall j$

$\in($ ASIGSEM $[s] \cap A S I G B L O[b]), k \in$ PROFASIG $[j]$

Times a week that a course can be taught:

Each course $\mathrm{j}$ of a semester $\mathrm{s}$ and with a time block b, must be taught exactly Pj times a week.

$$
\begin{aligned}
& \sum_{d \in \text { DIA }} \sum_{i \in \text { SALON }} \sum_{k \in \text { PROFASIG }[j]} X_{i s b j k d}=P_{j} \\
& \forall b \in \text { BLOQUEH, } \forall s \in \text { SEMESTRE, } \forall j[(\text { ASIGSEM }[s] \cap \text { ASIGBLO }[b])
\end{aligned}
$$

Where $P_{j}$ is the times a week a course $\mathrm{j} \in$ ASIGNATURA will be taught

\section{$\underline{\text { Time slots contraints }}$}

For BLOQUEH = 1:

On a day $d$, for each semester $s$, considering the course $j[s]$ corresponding to type-1 time slot 1 , it can be scheduled at most one course associated with one classroom $\mathrm{i}$ and one teacher $\mathrm{k}$.

$$
\begin{array}{r}
\sum_{i \in \text { SALON }} \sum_{j \in A S I G S E M[s]} \sum_{k \in P R O F A S I G[j]} X_{i s 1 j k d} \leq 1 ; \\
\forall d \in D I A, \forall s \in \text { SEMESTRE }, \quad b=1
\end{array}
$$

For BLOQUEH = 2:

On a day $d$, for each semester $s$, considering the course j[s] corresponding to type- 2 time slot, it can be scheduled at most one course associated with one classroom $\mathrm{i}$ and one teacher $\mathrm{k}$. 


$$
\begin{aligned}
& \sum_{i \in S A L O N} \sum_{j \in A S I G S E M[s]} \sum_{k \in P R O F A S I G[j]} X_{i s 2 j k d} \leq 2 ; \\
& \forall d \in D I A, \quad \forall s \in \text { SEMESTRE }, \quad b=2
\end{aligned}
$$

In addition, a constraint is created to avoid the conflict between the two previous constraints. On a day $d$, for each semester s, it must be scheduled at most one course of the type-1 time slot or two courses of the type- 2 time slot.

$$
\begin{gathered}
\sum_{i \in S A L O N} \sum_{j \in A S I G S E M[s]} \sum_{k \in \text { PROFASIG }[j]} X_{i s 1 j k d}+\frac{\sum_{i \in S A L O N} \sum_{j \in A S I G S E M[s]} \sum_{k \in P R O F A S I G[j]} X_{i s z j k d}}{2} \leq 1 \\
\forall d \in D I A, \quad \forall s \in \text { SEMESTRE }
\end{gathered}
$$

\section{Classroom capacity constraints:}

The number of students $E S T_{j}$ in course j must not exceed the capacity of the assigned classroom $C A P_{i}$

$$
\begin{gathered}
X_{i s b j k d} \leq 1+\left(C A P_{i}-E_{j} T_{j}\right) \\
\forall d \in D I A, \forall i \in S A L O N, \forall s \in S E M E S T R E \\
\forall b \in \text { BLOQUEH, } \forall j \in \text { ASIGNATURA }, k \in \text { PROFESOR }
\end{gathered}
$$

Teacher crossing constraints:

For BLOQUEH = 1:

On a day $\mathrm{d}$, teacher $\mathrm{k}$ can be scheduled at most to one course $\mathrm{j}[\mathrm{s}]$, associated with a semester s, corresponding to type-1 time slot, in classroom i.

$$
\begin{aligned}
& \sum_{s \in \text { SEMESTRE }} \sum_{j \in \text { ASIGSEM }[s]} \sum_{i \in \text { SALON }} X_{i s 1 j k d} \leq 1 ; \\
& \forall d \in D I A, \quad \forall k \in \text { PROFESOR }, \quad b=1
\end{aligned}
$$

For BLOQUEH = 2:

On a day $d$, teacher $\mathrm{k}$ can be scheduled at most to one course $\mathrm{j}[\mathrm{s}]$, associated with a semester s, corresponding to type-2 time block, in classroom i. 


$$
\begin{array}{r}
\sum_{s \in S E M E S T R E} \sum_{j \in \operatorname{ASIGSEM}[s]} \sum_{i \in S A L O N} X_{i s 2 j k d} \leq 2 ; \\
\forall d \in D I A, \quad \forall k \in \text { PROFESOR, } \quad b=2
\end{array}
$$

In addition, a constraint is created that avoids the conflict between the two previous constraints. On a day d, each teacher k, must be scheduled at most to one course of the type-1 time slot or two courses of the type- 2 time slot.

$$
\begin{gathered}
\sum_{s \in S E M E S T R E} \sum_{j \in A S I G S E M[s]} \sum_{i \in S A L O N} X_{i S 1 j k d}+\frac{\sum_{s \in S E M E S T R E} \sum_{j \in A S I G S E M[s]} \sum_{i \in S A L O N} X_{i s 2 j k d}}{2} \leq 1 ; \\
\forall d \in D I A, \quad \forall k \in \text { PROFESOR }
\end{gathered}
$$

\subsubsection{Objective function}

The objective function focuses on maximizing the number of courses scheduled F.O:MAX

$$
\sum_{d \in D I A} \sum_{k \in P R O F A S I G[j]} \sum_{j \in(\text { ASIGSEM }[S] \cap} \sum_{A S I G B L O[b])} \sum_{b \in B L O Q U E H} \sum_{s \in S E M E S T R E} X_{i s b j k d}
$$

\subsection{Aplication of the mathematical model}

For the application of the model, the sets, subsets and parameters were particularly defined as follows:

\subsubsection{Sets}

SALON: 10 classrooms

DIA: 6 days

ASIGNATURA: 63 courses

SEMESTRE: 10 semesters

BLOQUEH: the two type of time slots were included: 1 for the type-1time slot for the 3-hour slot and 2 for the type-2 time slot for the 2-hour slot.

PROFESOR: all available teachers were considered.

Subsets were also defined according to Table 2. 


\subsubsection{Parameters}

Parameter Pj defined the courses taught once and twice a week.

CAPi assigned the capacity of each of the 10 classrooms.

On the other hand, ESTj presents the expected number of students for each subject.

\section{Model solution and results}

The model was solved using the CPLEX solver and the AMPL programming language. The results show the following main elements:

- The 63 courses were satisfactorily programmed and, therefore, the objective function is fulfilled.

- On the same day, the courses have different rooms, assigned without any crossing.

- On the same day, in the same room, there is only one course assigned. Courses to be scheduled twice a week $(\mathrm{Pj}=2)$ are properly assigned.

- The constraint R3 was complied. The 2-hour and 3-hour courses were assigned only once and the 4-hour courses were assigned twice and on different days of the week.

- In a semester, on the same day, there are no crossings between courses, and the compliance of constraints $R 4 a, R 4 b, R 4 c$ and $R 5$ is verified.

- In a week, teachers are scheduled once a day for 3-hour courses and twice a day for 2-hour courses. This indicates compliance with the teacher restrictions $\mathrm{R} 6 \mathrm{a}, \mathrm{R} 6 \mathrm{~b}$ and $\mathrm{R} 6 \mathrm{c}$ of the model.

The above optimal results are associated with the best way to do what the institution already does, and in this article this was taken as the optimal base scenario or scenario 1. Given that the institution had multiple difficulties at all levels in these manual scheduling processes, the benefits in agility and precision are immediate with the proposed model, and easy to recognize although difficult to measure. For this reason, it was decided to compare this optimal scenario 1 with another ideal scenario for the institution, which was associated with the non-use of Saturdays for classes. They wanted to minimize the number of courses assigned on Saturday, which was also seen as a relevant objective. That other scenario involved the addition of a new binary variable to assign or not a course on Saturdays and the design of a new constraint. For this article this context was considered as scenario 2 and we show below the adjustments of the model in this regard.

Based on the formulated and validated model, an additional constraint (R7) was designed that corresponds to the additional requirements presented in the real case study: "classes should be scheduled from Monday to Friday, avoiding Saturdays". This new constraint, in which $d=6$, implies that a new variable $W$ should be equal to the sum of all assignments generated on Saturday, and this allows us to later minimize $W$ in the objective function.

$$
W=\sum_{k \in P R O F A S I G[j]} \sum_{j \in(A S I G S E M(S] \cap} \sum_{A S I G B L O[b])} \sum_{b \in \text { BLOQUEH }} \sum_{S \in S E M E S T R E} \sum_{i \in \text { SALON }} X_{i s b j k 6}
$$

$$
d=6(R 7)
$$


Therefore, the term (-W) was added to the objective function in such a way that, while maximizing the number of total assignments, it minimized the number of assignments on Saturdays.

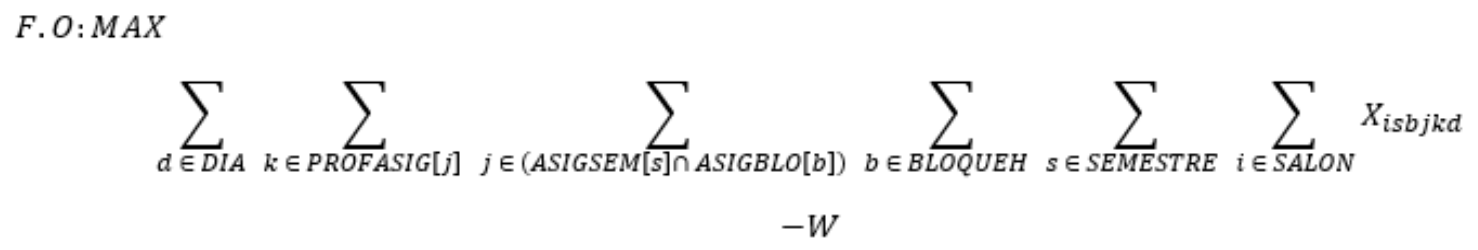

Table 4 shows the solution of both scenarios where 66 courses were optimally assigned in each case.

Table 4

Relevant results of the scenarios

\begin{tabular}{|c|c|c|c|c|c|c|}
\hline & \multicolumn{3}{|c|}{ SCENARIO 1} & \multicolumn{3}{|c|}{ SCENARIO 2} \\
\hline & $\begin{array}{c}\text { Assigned } \\
\text { courses }\end{array}$ & $\begin{array}{c}\text { Teachers } \\
\text { assigned per } \\
\text { day }\end{array}$ & $\begin{array}{c}\text { Teachers } \\
\text { assigned the } \\
\text { same day } 2 \\
\text { times }\end{array}$ & $\begin{array}{c}\text { Assigned } \\
\text { courses }\end{array}$ & $\begin{array}{c}\text { Teachers } \\
\text { assigned per } \\
\text { day }\end{array}$ & $\begin{array}{c}\text { Teachers } \\
\text { assigned the } \\
\text { same day } 2 \\
\text { times }\end{array}$ \\
\hline Monday & 12 & 11 & 1 & 15 & 11 & 4 \\
\hline Tuesday & 11 & 11 & 0 & 11 & 11 & 0 \\
\hline Wednesday & 12 & 11 & 1 & 10 & 10 & 0 \\
\hline Thursday & 11 & 10 & 1 & 13 & 12 & 1 \\
\hline Friday & 8 & 8 & 0 & 15 & 15 & 0 \\
\hline Saturday & 12 & 12 & 0 & 2 & 2 & 0 \\
\hline
\end{tabular}

Table 4 shows a reduction of assignments on Saturdays as expected, passing from 12 assignments in scenario 1 , to 2 assignments with the new model configuration in scenario 2. This will allow generating a direct increase in student satisfaction. Sin embargo, en el escenario 2 hay más profesores que se asignan a más de un curso (2) en el mismo día, lo cual podría descrementar la satisfacción de los docentes. A pesar de ello, conociendo que en la institución analizada, el menor trabajo de los docentes el sábado también incrementa la satisfacción general, podria decirse que el escenario 2 es satisfactorio.

The diffusion of these results in this pilot test, allowed the institution's authorities to consider some research extensions in the near future with other particular considerations. Here we present some research proposals derived from the analysis of the developed model:

- To identify constraints that allow a better solution. For example, for future research two conditions that were previously considered need to be reinforced: to take into account that in one day a teacher can stay in the same classroom with two 2-hour courses; to consider that in one day two 2-hour courses of the same semester can be scheduled in the same classroom.

- To include facility constraints like distance between the classrooms because there are two different buildings far from each other, and the time spent in going to the classrooms can be important.

- To consider that some 3-hour courses could be split into 1 and 2 hours, including a cost factor for the use of rooms.

- To Scale the model for all programs of the Institution. 


\section{Conclusions}

The proposed timetabling mathematical model and its solution and success allowed the institution to trust in the optimization methodology and to establish an expanded strategy, opening possibilities to advanced tools in the near future.

According to the results, the mixed integer linear programming was a suitable method to deal with this timetabling problem, giving an exact solution. However, in an extension of this research it is clear that the suitability of exact methods needs to be revised, depending on new modeling demands and data sets.

The use of optimization models in real life may sometimes not be possible due to financial and other limitations. That is why it is very useful to perform pilot tests with the use of optimization models with which important doors are opened for larger-scale implementations in reality.

\subsection{Acknowledgements}

We thank the School of Industrial Engineering of the Universidad del Valle, as well as the institution that provided the data and the case to be analyzed, for supporting this research.

\section{References}

Babaei, H., Karimpour, J., \& Hadidi, A. (2015). A survey of approaches for university course timetabling problem. Computers and Industrial Engineering, 86, 43-59, https://doi.org/10.1016/j.cie.2014.11.010.

Bravo, J.J. (2013). Optimización de decisiones empresariales. Principios de descomposición, jerarquización y dualidad. Programa Editorial Universidad del Valle, 238 p. http://programaeditorialunivalle.com/librooptimizacion-de-decisiones-empresariales-principios-de-descomposicion-44-jerarquizacion-y-dualidadadministracion.html

Dorneles, Á. P., De Araújo, O. C. B., \& Buriol, L. S. (2014). A fix-and-optimize heuristic for the high school timetabling problem. Computers and Operations Research, 52, 29-38. https://doi.org/10.1016/j.cor.2014.06.023.

Esquivel, L.L. \& Orejuela, J.P. (2019). Programación de horario escolar con multi-localización y preferencias docentes. Revista Logos Ciencia \& Tecnología, 11(1), 20-29, https://doi.org/10.22335/rlct.v11i1.621.

Even, S., Itai, A., \& Shamir, A. (1976). On the Complexity of Timetable and Multicommodity Flow Problems. SIAM Journal on Computing, 5(4), 691-703. https://doi.org/10.1137/0205048.

Fonseca, G. H. G., Santos, H. G., Carrano, E. G., \& Stidsen, T. J. R. (2017). Integer programming techniques for educational timetabling. European Journal of Operational Research, 262(1), 28-39. https://doi.org/10.1016/j.ejor.2017.03.020.

Heitmann, H., \& Brüggemann, W. (2014). Preference-based assignment of university students to multiple teaching groups. OR Spectrum, 36(3), 607-629. https://doi.org/10.1007/s00291-013-0332-9.

Kristiansen, S., Sørensen, M., \& Stidsen, T. R. (2015). Integer programming for the generalized high school timetabling problem. Journal of Scheduling, 18(4), 377-392. https://doi.org/10.1007/s10951-014-0405-x.

Song, T., Liu, S., Tang, X., Peng, X., \& Chen, M. (2018). An iterated local search algorithm for the University Course Timetabling Problem. Applied Soft Computing Journal, 68, 597-608.

https://doi.org/10.1016/j.asoc.2018.04.034. 
Thepphakorn, T., Pongcharoen, P., \& Hicks, C. (2014). An ant colony based timetabling tool. International Journal of Production Economics, 149, 131-144. https://doi.org/10.1016/j.ijpe.2013.04.026.

Torres Ovalle, C., Montoya Torres, J., Quintero Araújo, C., Sarmiento Leperqueur, A., \& Castilla Luna, M. (2014). University Course Scheduling and Classsroom Assignment. Ing. Univ. Bogotá (Colombia), 18(1), 59-75. 10.11144/Javeriana.IYU18-1.phaa.

Toune, S., Fudo, H., Genji, T., Fukuyama, Y., \& Nakanishi, Y. (2002). Comparative study of modern Heuristic algorithms to service restoration in distribution systems. IEEE Transactions on Power Delivery, 17(1), 173181. https://doi.org/10.1109/61.974205.

Wren, A. (1996). Scheduling, timetabling and rostering - A special relationship?. In E. Burke \& P. Ross (Eds.) (pp. 46-75). Practice and Theory of Automated Timetabling . Lecture Notes in Computer Science, vol 1153. Springer, Berlin, Heidelberg. https://doi.org/10.1007/3-540-61794-9_51.

Esta obra está bajo una Licencia Creative Commons Attribución-NoCommercial 4.0 International

\section{$(\mathrm{cc})$ BY-NC}

